\title{
Safety and Efficacy of a Standardized Extract from Leaves of Dalbergia Sissoo in Healing of Long Bone Fracture: A Pilot Clinical Study
}

\author{
Dixit Pankaj ${ }^{1}$, Pande Shishir ${ }^{1}$ and Deshmukh Amol ${ }^{2 *}$ \\ ${ }^{1}$ Ayurved Seva Sangh Ayurved College and Hospital, India \\ ${ }^{2}$ Pharmanza Herbal Pvt.Ltd, India
}

Submission: February 03, 2017; Published: January 25, 2018

*Corresponding author: Deshmukh Amol, Pharmanza Herbal Pvt.Ltd. BorsadTarapur Road, Near Dharmaj Cross Road, Dharmaj, Gujarat 388 435, India, Tel: 09898652936; Email: dr.amoldeshmukh99@gmail.com

\begin{abstract}
Introduction: Healing of long bone fracture is a complex phenomenon and usually take months to years to recover completely. Varied products from different systems of medicine have been tried to accelerate fracture healing process. In recent preclinical studies it is found that standardized extract of leaves of Dalbergia sissoo accelerated fracture healing in rats by stimulating bone regeneration. The bone regeneration activity of herb is attributed to a novel compound CAFG.
\end{abstract}

Aim: To evaluate the safety and efficacy of a standardized extract of Dalbergia sissoo (DSE) leaves in patients with long bone fracture.

Materials and Methods: This was a single arm, pilot clinical study conducted at Nashik, Maharashtra. A total of 16 patients with lower or upper limbs long bone fracture were enrolled in this study to receive oral 300mg DSE capsules (twice daily for 2 months). The primary endpoint was fracture healing, assessed radiologically at week 2,4,6 and 8. Safety was evaluated by monitoring adverse event and biochemical investigations.

Results: Treatment with DSE resulted in fading of fracture line in subsequent follow up visits and restored functional mobility. At the end of the study (week 8) all fractures were healed. No clinically significant adverse events were reported. At the end of the study, SGOT, SGPT and urea were significantly reduced compared with baseline.

Conclusion: Overall, this study demonstrated that a standardized extract of DSE leaves was well tolerated with no safety concern and has a potential of fracture healing.

Keywords: Dalbergia sissoo extract; CAFG; Fracture healing

Abbreviations: DSE: Dalbergia Sissoo Extract; SGOT: Serum Glutamic Oxaloacetic Transaminase; SGPT: Serum Glutamic Pyruvic Transaminase

\section{Introduction}

Fracture healing is a complex cascade that involves many local and systemic regulatory factors, cytokines and hormones that recapitulates the sequential stages of embryonic endochondral ossification [1]. A few hours after the occurrence of fracture, the extra vascular blood cells clot and form a hematoma. This fracture hematoma is enriched with several signalling molecules including interleukin(IL)-1, IL-6, tumor necrosis factor- $\alpha$ (TNF- $\alpha$ ), transforming growth factor $\beta$ (TGF $\beta$ ), fibroblast growth factors (FGF), insulin-like growth factor (IGF), platelet-derived growth factor (PDGF) and vascular endothelial growth factor (VEGF). These factors regulate subsequent recruitment of endothelial cells, platelets, macrophages, monocytes and multi potent mesenchymal stem cells at fracture site and induce a cascade of cellular events to recruit osteoblast and osteoclast $[2,3]$. These loose aggregate of cells with several growth factors, interspersed with small blood vessels is known as granulation tissue. The phase of granulation tissue formation is termed as reactive phase. This reactive phase precedes the reparative phase of healing which involves cartilaginous soft callus formation. Subsequently, the cartilaginous callus is resorbed and gradually replaced with woven bone, which is ultimately mineralized and undergo remodelling event to restore the original cortex of the lamellar bone [4].

Although there are quite a few clinical agents to manage bone pathology there is no orally active pharmacological agent for rapid fracture healing. As a result, traditional remedies are 
being re-evaluated through reverse pharmacology to validate the efficacy and discover novel pharmacological agent for clinical interventions [5].

An ayurvedic herb Cissus quadrangularis (CQ) is used traditionally for accelerating process of fracture healing. There are few clinical studies reporting the role of CQ in fracture healing, the compound(s) responsible for such effect remains unknown [6-10]. Recent preclinical studies have shown that a standardized extract made from leaves of Dalbergiasissoo (DSE) has significant osteogenic effect which was attributed to a novel compound caviunin 7-0-[ $\beta$-D-apiofuranosyl- $(1 \rightarrow 6)-\beta$-Dglucopyranoside(CAFG) [11,12]. In rodents, CAFG accelerated fracture healing by stimulating bone regeneration at the fracture site with 1- and $5 \mathrm{mg} / \mathrm{kg}$ oral dose [12].

Hence, this pilot clinical study was designed to assess the safety of DSE in patients with long bone fracture. In addition, efficacy of DSE was also assessed to support further development of this drug for potential use in this population.

\section{Materials and Methods}

\section{Study design}

This was a prospective, interventional, single-centre, single arm, pilot clinical study conducted at Nashik, Maharashtra (Clinical trial registration no. CTRI/2015/06/005850). Patients with long bone fracture(s) of upper or lower arm visiting Shalya Tantra outpatient department of Ayurved Seva Sanga Hospital, Nashik, were screened and enrolled if fulfilled eligibility criteria. Enrolled patients were provided with study medication (2 capsules of DSE, twice a day for 2 months). Study visits were planned on Day 15,30,45 and 60. At each study visit, clinical and radiological examinations were conducted to evaluate the safety and improvement in fracture healing. Biochemical investigations were done at baseline and at the end of study.

\section{Study participants}

Patients of either sex between 18 and 60 years of age with long bone fracture(s) of upper or lower arm (confirmed by radiological report) were enrolled in the study within 5 days from the day of fracture. Patients with pathological fractures, diabetes, end organ failure or pregnant women excluded from the study.

The study was conducted in accordance with the principles that have their origin in the Declaration of Helsinki (2013) and that are consistent with International Conference on Harmonization (ICH) guidelines on Good Clinical Practices (GCP) and applicable regulatory requirements. The study protocol was reviewed and approved by the Institutional Ethics Committee. Written informed consent was obtained from each patient for participation in this study.

\section{Study medication}

Capsules containing $300 \mathrm{mg}$ of alcoholic extract of DSE leaves were supplied by Pharmanza Herbal Pvt. Ltd. The extract is based on a patent (EP 2705047 B1) which owned by Council of Scientific and Industrial Research, New Delhi, India. DSE contained Caviunin-70-[ $\beta$-D-apiofuranosyl- $(1 \rightarrow 6)-\beta-D-$ glucopyranoside(CAFG) $0.67 \%$, Biochanin-7-0-glucoside $1.5 \%$, Genstein 0.75\%, Pratensein 0.2\% and Biochanin-A, 1\%.

\section{Assessments}

Assessment included fracture healing (clinical and radiological). Clinical assessment included fracture site pain and functionality (ability to walk or perform daily activities). Pain was assessed using visual analogue scale (VAS) having score from 0 to 10 (lesser the score greater the improvement) and functionality (patient's ability to walk or perform daily activity) was graded from 0 to 3 (greater score shows greater improvement). Radiological criteria included fading of fracture line in x-rays of subsequent follow-up visits. Safety was assessed throughout the study duration. At baseline and at the end of study, levels of serum glutamic oxalo acetic transaminase (SGOT) and serum glutamic pyruvic transaminase (SGPT) were also recorded to assess hepatotoxicity, and blood urea nitrogen (BUN) and serum creatinine levels to assess renal toxicity. Serum biochemical parameters were measured by Automated-analyzer (Sysmex) using kinetic assay method [13-15].

\section{Statistical Analysis}

Baseline scores of clinical biochemical parameters of all patients were compared with the scores of their clinical and biochemical parameters on study Day 15,30,45 and 60. Effect of treatment was analyzed by using paired student's t test with significance level of 0.01 .

\section{Results}

Total twenty patients with long bone fractures were enrolled in the study and of which 16 patients completed the study. Four patients withdrew consent and excluded from the analysis. The mean age of patients who completed the study was 39.6 years which ranged from 30 to 52 years. The fracture sites were humerus, ulna, fibula (25\%; $n=4$, each) and radius and tibia (12.5\%; $n=2$, each). At baseline, the mean (SD) VAS score for fracture pain was 9.1(0.6) which reduced significantly $(\mathrm{p}<0.01)$ to $1.1(1.2)$ by the end of the study. Baseline VAS score for pain experienced by patient at the time of examination (palpation) of fracture site was 9.6(0.7) which reduced significantly $(\mathrm{p}<0.01)$ to $0.9(1.2)$ in 8 weeks. Patient's ability to walk or perform daily activities improved significantly $(\mathrm{p}<0.01)$ from baseline $0(0)$ to 2.1(0.8) by end of the study (Table1).

\section{Radiological assessment}

Radiological assessment which was performed to confirm clinical fracture healing showed fading of fracture line in subsequent study visits. Fracture line which was visible at the baseline faded in subsequent study visits (Figure $1 \& 2$ ). 

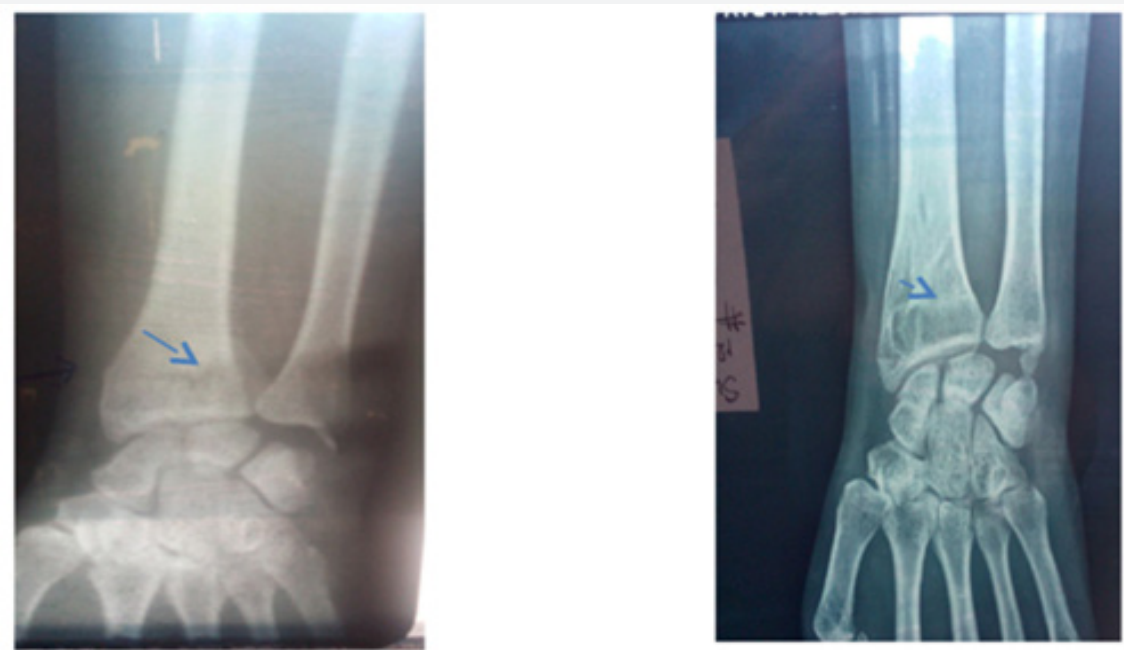

Radius fracture before treatment (day0)

Radius fracture after treatment ( $8^{\text {th }}$ week)

Figure 1: X-Ray of radius fracture before treatment and after treatment.

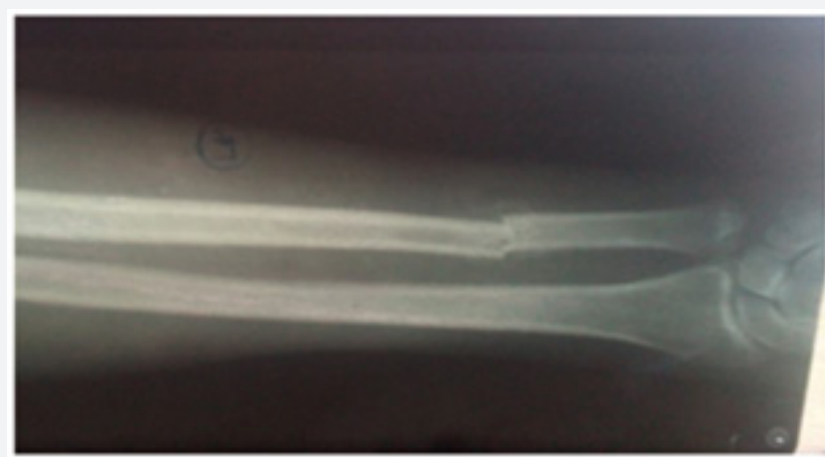

Ulna fracture before treatment (day0)

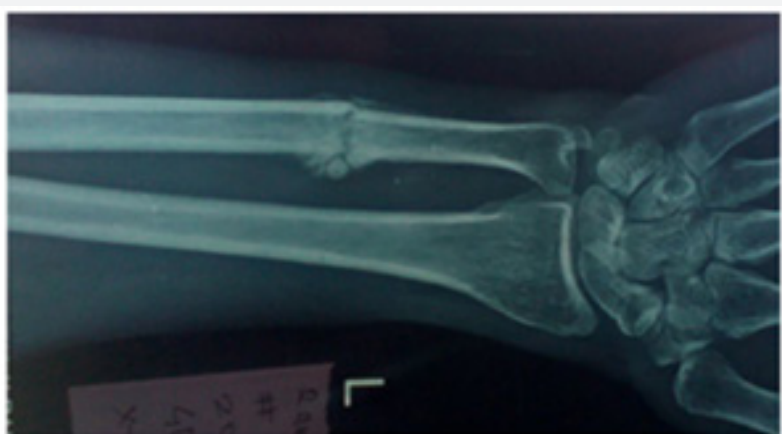

Ulna fracture after treatment ( $8^{\text {th }}$ week)

Figure 2: X-Ray of ulna fracture (before treatment and after treatment).

\section{Biochemical parameters}

The mean (SD) SGOT, SGPT and urea at the baseline were 32.3(15) IU, 31.6(13.6) IU, and 30.9(5.4)mg\%, respectively, which reduced significantly $(\mathrm{P}<0.01)$ at the end of study visit to 24.9(9.7) IU, 25(9.3) IU and 27.3(2.9) $\mathrm{mg} \%$. The level of creatinine at baseline was $1.0(0.2) \mathrm{mg} \%$, which was $1.0(0.2) \mathrm{mg} \%$ in the end of study $(\mathrm{P}>0.01)$ (Table 1$)$.

Table 1: Level of clinical and haematological parameters at baseline and at follow up visits.

\begin{tabular}{|c|c|c|c|c|c|c|}
\hline Clinical Parameters & & Base Line & $\begin{array}{c}1^{\text {st }} \text { Visit } \\
\left(2^{\text {nd }} \text { Week }\right)\end{array}$ & $\begin{array}{c}2^{\text {nd }} \text { Visit } \\
\left(4^{\text {th }} \text { Week }\right)\end{array}$ & $\begin{array}{c}3^{\text {rd }} \text { Visit } \\
\left(6^{\text {th }} \text { Week }\right)\end{array}$ & $\begin{array}{c}4^{\text {th }} \text { Visit } \\
\left(8^{\text {th }} \text { Week }\right)\end{array}$ \\
\hline \multirow{4}{*}{ Pain } & Mean(SD) & $9.125(0.62)$ & $6.875(1.83)$ & $4.875(1.97)$ & $3(2.07)$ & $1.125(1.21)$ \\
\hline & t score & & 6.267 & 9.711 & 12.922 & 25.237 \\
\hline & $\mathrm{p}$ & & $<0.01$ & $<0.01$ & $<0.01$ & $<0.01$ \\
\hline & signifiance & & significant & significant & significant & significant \\
\hline \multirow{4}{*}{$\begin{array}{c}\text { Pain/ Tenderness While Examining } \\
\text { Fracture Area }\end{array}$} & Mean(SD) & $9.625(0.72)$ & $6.625(2.63)$ & $4.75(2.87)$ & $2.625(2.19)$ & $0.875(1.21)$ \\
\hline & t score & & 5.068 & 7.076 & 13.54 & 26.042 \\
\hline & $\mathrm{p}$ & & $<0.01$ & $<0.01$ & $<0.01$ & $<0.01$ \\
\hline & significance & & significant & significant & significant & significant \\
\hline
\end{tabular}


Journal of Complementary Medicine \& Alternative Healthcare

\begin{tabular}{|c|c|c|c|c|c|c|}
\hline \multirow{4}{*}{$\begin{array}{l}\text { Ability to Walk or Perform Daily } \\
\text { Activities with no Pain }\end{array}$} & Mean(SD) & $0(0)$ & $0.25(0.45)$ & $0.875(0.81)$ & $1.5(0.74)$ & $2.125(0.81)$ \\
\hline & t score & & 2.24 & 4.34 & 8.2 & 10.52 \\
\hline & $\mathrm{p}$ & & $<0.05$ & $<0.01$ & $<0.01$ & $<0.01$ \\
\hline & significance & & significant & significant & significant & significant \\
\hline \multicolumn{7}{|c|}{ Hematological Parameters } \\
\hline \multirow{4}{*}{ SGOT(IU) } & Mean(SD) & $32.25(14.96)$ & & & & $24.87(9.67)$ \\
\hline & t score & & & & & 3.33 \\
\hline & $\mathrm{p}$ & & & & & $<0.01$ \\
\hline & significance & & & & & significant \\
\hline \multirow{4}{*}{ SGPT(IU) } & Mean(SD) & $31.62(13.63)$ & & & & $25(9.23)$ \\
\hline & t score & & & & & 3.34 \\
\hline & $\mathrm{p}$ & & & & & $<0.01$ \\
\hline & significance & & & & & significant \\
\hline \multirow{4}{*}{ Urea(mg \%) } & Mean(SD) & $30.875(5.36)$ & & & & $27.25(2.91)$ \\
\hline & t score & & & & & 3.69 \\
\hline & $\mathrm{p}$ & & & & & $<0.01$ \\
\hline & significance & & & & & significant \\
\hline \multirow{4}{*}{ Creatinine(mg \%) } & $\operatorname{Mean}(\mathrm{SD})$ & $1.0125(0.22)$ & & & & $0.97(0.15)$ \\
\hline & t score & & & & & 1.22 \\
\hline & $\mathrm{p}$ & & & & & $>0.05$ \\
\hline & significance & & & & & insignificant \\
\hline
\end{tabular}

SGOT: Serum Glutamic Oxaloacetic Transaminase; SGPT: Serum Glutamic Pyruvic Transaminase; SD: Standard Deviation.

\section{Discussion}

To authors knowledge this was the first study to assess fracture healing properties of DSE in humans. Results from this pilot study demonstrated that administration of DSE in patients with long bone fracture was generally tolerable with no safety concerns. At the end of the study all patients were comfortable in doing their daily routine activities with minimal pain or discomfort. After treatment with study medication these patients showed significant improvement in all clinical parameters consistently throughout the study visits. Radiological assessment revealed the fading of fracture line which confirmed the clinical healing of the fractures. The average healing time for such long bone fracture is said to be between $12-16$ weeks $[16,17]$ which was reduced approximately by $30-40 \%$ with the use of DSE.

These results support the similar observations noted during the preclinical studies, where DSE showed increased bone regeneration at the fracture site of rat long bone. The CAFG, an osteogenic compound present in DSE, promoted bone regeneration at the site of fracture in long bones of ovary-intact and ovariectomized mice [12].

In a fracture healing study when 10 interlocked nail fixed fracture patients treated with the poly-herbal formulation containing CQ (UNIBONE capsules) the fractures were found to have healed in 12-14 weeks. The average fracture healing time for those patients was said to be 16-20 weeks, which was decrease by $25-30 \%$ with the use of UNIBONE [6]. When the fracture healing efficacy was compared in adult rats between CQ and DSE given per oral, the later was found to be more effective (unpublished data, personal communication with Dr.Naibedya Chattopadhyay, CSIR-Central Drug Research Institute, Lucknow, India).

Overall, administration of DSE in patients with long bone fracture was well-tolerated with no safety signals. There were no deaths, serious adverse events, or discontinuations due to adverse events during the study. One female patient reported stomach upset which was relieved without any medication before study completion. The baseline levels of SGOT, SGPT and urea were reduced significantly by the end of the study. Though the reduction in the level of creatinine was not significant ( $p>0.05)$, the values of creatinine were in normal limits. This indicates safety of DSE when taken in the doses of $1200 \mathrm{mg} /$ day for the period of 2 months.

Authors acknowledge following limitations of this study. The study was limited with 1) small sample size, 2) fractures of different sites, 3) no comparator (active or placebo). Authors also acknowledge that it could be difficult to explain if the fracture healing was due to natural process or due to DSE, however based on previous data we hypothesize that DSE has the potential to accelerate the healing of fracture. Further studies with larger sample size and using fracture healing biomarkers, more detailed radiological and biochemical investigations are warranted to confirm these results. 


\section{Conclusion}

Though the study was limited by small sample size with no direct comparator, it provides insights on the safety and efficacy of DSE in the patients with long bone fracture. Long term study with larger size using fracture healing biomarkers is warranted to confirm these results.

\section{Acknowledgement}

Authors would like to thank Pharmanza Herbal Pvt. Ltd. for providing study medication and fund for the study.

\section{References}

1. Perren SM (1979) Physical and biological aspects of fracture healing with special reference to internal fixation. Clin Orthop Relat Res 138: 175-196.

2. Giannoudis PV, Einhorn TA, Marsh D (2007) Fracture healing: the diamond concept. Injury 38(4): 3-6.

3. Tsiridis E, Upadhyay N, Giannoudis P (2007) Molecular aspects of fracture healing: which are the important molecules? Injury 38(1): 11 25 .

4. Hankenson KD, Gagne K, Shaughnessy M (2015) Extracellular signaling molecules to promote fracture healing and bone regeneration. Adv Drug Deliv Rev 94: 3-12.

5. Phillipson JD, Anderson LA (1989) Ethnopharmacology and western medicine. J Ethnopharmacology 25(1): 61-72.

6. Thawani V, Kimmatkar N, Hingorani L, Khiyani R (2002) Effect of herbal combination containing cissusquadrangularis in fracture healing. The Antiseptic 99(9): 345-347.

7. Prasad GC, Udupa KN (1970) Role of cissusquadrangularis on fracture healing. Advances in research in Indian medicine 12: 163-196.
8. Sing V, Sing N, Pal U, Dhasmana S, Mohammad S, et al. (2011) Clinical evaluation of cissusquadrangularis and moringaoleifera and osteoseal as osteogenic agents in mandibular fracture. Natl J Maxillofac Surg 2(2): 132-136.

9. Mohammad S, Pal U, Pradhan R, Singh N (2014) Herbal remedies for mandibular fracture healing. Natl J Maxillofac Surg 5(1): 35-38.

10. Udupa KN, Prasad GC (1964) Further studies on the effect of Cissusquadrangularis in accelerating fracture healing. Ind J Med Res 52: 26-35.

11. Khedgikar V, Gautam J, Kushwaha P, Kumar A, Nagar GK, et al. (2012) A standardized phytopreparation from an Indian medicinal plant (Dalbergiasissoo) has antiresorptive and bone-forming effects on a postmenopausal osteoporosis model of rat. Menopause 19(12): 13361346.

12. Kushwaha P, Khedgikar V, Gautam J, Dixit P, Chillara R, et al. (2014) A novel therapeutic approach with Caviunin-based isoflavonoid that en routes bone marrow cells to bone formation via BMP2/Wnt-betacatenin signaling. Cell Death Dis 5: 1422.

13. Schumann G, Bonora R, Ceriotti F, Ferard G, Ferrero CA, et al. (2002) IFCC reference procedure for aspartate aminotransferase. Clin Chem Lab Med 40(7): 725-733.

14. Jung D, Biggs H, Erikson J (1975) New Colorimetric reaction for endpoint, continuous-flow, and kinetic measurement of urea. Clin Chem 21(8): 1136-1140.

15. Young DS, Pestaner LC, Gibberman V (1975) Effects of drugs on clinical laboratory tests. Clin Chem 21(5): 1D-432D.

16. Hsueh TP, Chiu HE (2012) Traditional Chinese medicine speeds-up humerus fracture healing: two case reports. Complement Ther Med 20(6): 431-433.

17. Hanson B, Neidenbach P, de Boer P, Stengel D (2009) Functional outcomes after nonoperative management of fractures of the proximal humerus. J of Shoulder Elbow Surg 18(4): 612-621.

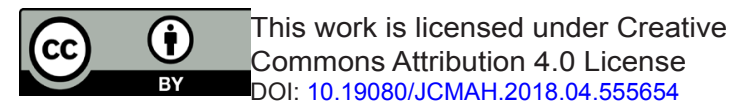

\begin{tabular}{l} 
Your next submission with Juniper Publishers \\
will reach you the below assets \\
- Quality Editorial service \\
- Swift Peer Review \\
- Reprints availability \\
- E-prints Service \\
- Manuscript Podcast for convenient understanding \\
- Global attainment for your research \\
- Manuscript accessibility in different formats \\
( Pdf, E-pub, Full Text, Audio) \\
- Unceasing customer service \\
Track the below URL for one-step submission \\
https://juniperpublishers.com/online-submission.php \\
\hline
\end{tabular}

